\title{
PREPARING A DATA BASE FOR ESTIMATING SEISMIC DAMAGE ON BUILDINGS BY APPLYING ANN
}

\author{
MSc Igor Peško* \\ University of Novi Sad, Faculty of Tehnical Science, Novi Sad, Serbia \\ Dr Jasmina Dražić \\ University of Novi Sad, Faculty of Tehnical Science, Novi Sad, Serbia \\ MSc Vladimir Mučenski \\ University of Novi Sad, Faculty of Tehnical Science, Novi Sad, Serbia \\ Dr Milan Trivunić \\ University of Novi Sad, Faculty of Tehnical Science, Novi Sad, Serbia
}

Seismic risk in urban areas increases over time, so the research projects on all the aspects of seismic safety carried out currently are numerous. In order to plan preventive measures, the estimation of possible damages on buildings plays a significant role. This paper describes preparation of a data base for predicting seismic damage category by applying artificial neural networks (ANN). The base will be defined relying upon the available data from the reports after the earthquake in Kraljevo (03/11/2010).

Keywords: earthquake, damage, data base, artificial neural networks

\section{INTRODUCTION}

Earthquakes present a natural hazard (geologic hazard), with consequences such as the loss of human lives as well as economic losses caused by damages on buildings (material destruction). Defining damage caused on buildings is significant in all the phases of an earthquake. During the pre-quake phase, possible damages are defined with the aim of planning of preventive measures as well as the basis for estimation of certain area's potential risks. Later on, immediately following the earthquake, it is done in order to rescue and shelter the victims, and in the phase after the earthquake, with the aim of undertaking measures to eliminate, reduce, and repair damages.

This paper describes a data base preparation with the aim of future estimation of damages on buildings caused by earthquakes, by applying artificial neural networks (ANN). The origins of development of neuro-computing are related to an article by McCulloch and Pitts:' A logical calculus of the ideas immanent in nervous activity' [1]. There is still no uniformed definition which completely explains neural networks. One of the definitions offered in scientific- technical books, from the engineer point of view, is 'a computational mechanism able to acquire, represent and compute mapping from one multivariate space of information to another, given a set of data representing that mapping.' [2]

Artificial neural networks imitate the functioning of biological neural networks, by using adequate mathematical models (of structures, functions and modes of processing). Mathematical model of an ANN consists of three basic segments: mathematical model of a neuron itself, network architecture (models of synaptic connections and structure of neurons within a network) and rules of network training. An artificial neural network is connected with its environment in two ways: by inputs through which the environment influences the artificial neural network, and by outputs, through which a neural network reciprocally influences its environment.

\section{SEISMIC ACTIVITY IN SERBIA}

According to a seismic map (for the period going 500 years backwards), over $90 \%$ of the territory of Serbia belongs to the VIII degree of MSK-64 scale, about $7 \%$ belongs to IX and only about $2-3 \%$ to VII degree of this scale, i.e. the whole 
territory of Serbia, according to this scale, is seismically active. Serbia is located in a seismically active zone, in its border part, the so called Mediterranean-trans Asiatic seismic zone, or more precisely, Mediterranean belt. Owing to its position on the very edge of the plate, earthquakes in Serbia, according to estimations of seismologists, cannot exceed 6.2 to 6.3 units of the Richter magnitude scale. The most severe earthquake which hit Serbia in the last 100 years occurred in the year 1922 in Lazarevac, with the 5.9 Richter scale magnitude. Earthquakes of 5.7 degrees hit Vitina in 1921, Rudnik in 1927, Kopaonik in 1980 and Mionica in 1998. Regarding their energy, these earthquakes can be destructive, too. Earthquake prone areas in Serbia are the following: the regions of Kopaonik, Rudnik, Krupaj, Maljen, Lazarevac, Svilajnac, Golubac, Urosevac-Gnjilane, Vranje and Kraljevo.
The last earthquake of a stronger intensity on the territory of Serbia occurred on November 3 , 2010 , at 1:56 am. Its magnitude was 5.4 degrees on the Richter scale. The time of the earthquake beginning in its focus was 00:56:54.76 GMT, with the focal depth of $13 \mathrm{~km}$. The epicenter coordinates are $43.762 \mathrm{~N}$ latitude and $20.713 \mathrm{E}$ longitude, with the epicenter located $121 \mathrm{~km}$ south from Belgrade, or $4 \mathrm{~km}$ north from Kraljevo. Figure 1 shows the location of the main quake's epicenter, on the outskirts of Sirca village. [3]

After the main earthquake, a series of following tremors were registered in the area. Their magnitudes ranged from 1.0 to 4.4 degrees of the Richter scale. Those quakes of 2 degrees and below were only detected by instruments and could not be felt. During the interval of time until $1 \mathrm{pm}$ on November 9, 2010, the cluster of 258 earthquakes in total were registered. [3]

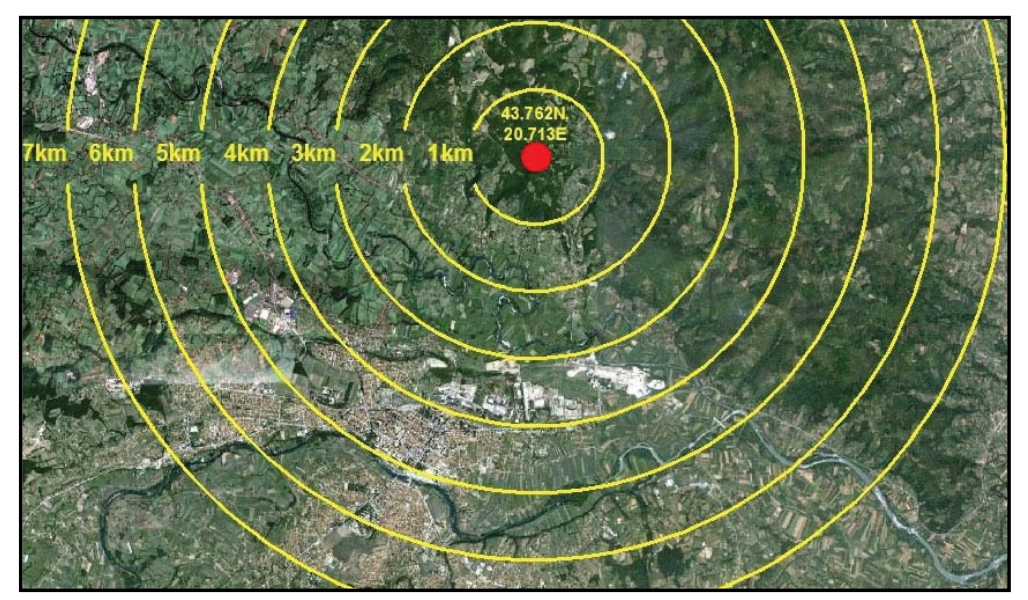

Figure 1. Epicenter of the main quake (Kraljevo, 03.11.2010)

\section{CREATING A DATA BASES}

In areas struck by earthquakes, seismic risk management and decisions that are to be made after they occur can play a vital role for the people residing in those areas. In order to calculate seismic risk, it is necessary to develop a correlation between a quake and the amount of damage for the buildings on the observed locality, i.e. to define buildings' vulnerability for the earthquake impact. Basic and the most important pre-condition for a high-quality functioning of a neural network is creation of an adequate data base for its training, i.e. defining input and output data. Creating a data base for seismic damage estimation is fully based upon reports made immediately after the earthquake which occurred on November 3 , 2010, near Kraljevo.

When creating a data base, it is necessary to pay attention to the future use of the ANN. 22
It is necessary for the input and output data to be available in the same form in the future as well. Such approach will completely provide later application of neural networks for the needs of predicting damages as consequences of future earthquakes impact.

In order to make a rough estimation of damages caused by the earthquake in Karaljevo, damages on buildings were identified. The data about the buildings for which the damage category was defined, in accordance with the enclosed classification, are given in table 1. Damages were divided into five categories (from 1 to 5 ). Category (0) belongs to buildings which suffered no damage, and the sixth category consists of totally destroyed buildings, as well as those which are not completely destroyed, but the amount of damage exceeds the level for which the reparation would be financially justi- 
Table 1. General data about the building from a report

\begin{tabular}{|c|c|}
\hline No. & Data about the building from the report \\
\hline 1. & Building address \\
\hline 2. & Year of construction, or the estimated age \\
\hline 3. & Building purpose (residential or business) \\
\hline 4. & Total number of flats \\
\hline 5. & Total number of business units \\
\hline 6. & Total number of above-ground storeys \\
\hline 7. & Total number of storeys (including underground storeys) \\
\hline 8. & Total gross area of a building \\
\hline \multirow{5}{*}{9.} & Type of construction: \\
\hline & - $\quad \mathrm{AB}$ skeletal or panel \\
\hline & $\begin{array}{l}\text { - Massive construction systems with horizontal and vertical ring beams and stiff inter-storey } \\
\text { construction }\end{array}$ \\
\hline & - Massive construction system with horizontal ring beams and stiff inter-storey construction \\
\hline & - Massive construction system with wooden inter-storey construction \\
\hline
\end{tabular}

fied. The categories, as well as the description of damage for each of them, were taken from the Instructions for determining category and damage level on earthquake-hit residential buildings, of the Serbian Chamber of Engineers [4]. As the basis for these instructions, the following documents were used:

- Regulations on technical normative for building construction in earthquake-prone areas (Official Gazette SFRJ 31/81, 48/82, 29/83, 21/88, 52/90);

- Regulations on technical normative for reparation, reinforcement and reconstruction of buildings damaged by earthquakes and for reconstruction and revitalization of building constructions. (Official Gazette SFRJ 52/85);

- Instructions for the common methodology for estimating damage caused by natural hazards (Official Gazette SFRJ 27/87).

Categories and descriptions of damages are shown in table 2.

Seismic resistance of a building is influenced by its architectural and construction features. Project solution and acquired configuration classify favorable and unfavorable forms of buildings in the base and cross section, whereas construction features based on its bearing capacity, ductility and stiffness of construction elements (interstorey construction, walls, pillars) are related to the type and materialization of the construction system [5].
Data presented in table 1, building purpose (residential-business), year of construc-tion, building height (number of floors and construction system type, provide direct connection between them (ANN inputs) and damage category (ANN outputs)

Within the data, the type of construction system comprises skeletal and panel constructions of reinforced cement and massive construction systems, with variants of reinforcement (horizontal or horizontal and vertical ring beams) and variants of inter-storey construction (stiff interstorey construction or wooden inter-storey construction).

Taking the structure of all the input data into consideration, it was realized that there is a possibility of obtaining derived input data. Based on the building address from the report, it is possible, by linking it to the geodetic map of the town of Kraljevo, to locate a building, identify its shape and base dimensions, define its distance from the main earthquake epicenter, as well as the earthquake's direction of propagation. The mentioned data are of great importance for defining the connection between the position of a building, earthquake location (distance between the building and the main quake epicenter $(L)$ ), and the caused damages.

As an illustration of the derived input data for artificial neural network training, figure 2 shows three buildings, different in position and distance related to the earthquake epicenter. 
Direction of propagation is defined by $\varphi$ angle (an angle that covers the direction of propagation related to the longitudinal axis of a building). After defining the $\varphi$ angle, it is possible to decompose seismic propagation on the longitudinal direction $(\mathrm{X})$ and transversal direction $(\mathrm{Y})$ of a building, and calculate the propagation distribution:

- DX - \% of earthquake propagation in the longitudinal direction of a building

- DY - \% of earthquake propagation in the transversal direction of a building.

Table 2.Damage category

\begin{tabular}{|c|l||}
\hline $\begin{array}{c}\text { Damage } \\
\text { category }\end{array}$ & Data from the report \\
\hline \hline 0 & Without damage \\
\hline I & $\begin{array}{l}\text { Minor damage - damages on the smaller areas of roofing, occurrence of minor cracks on plastered areas } \\
- \text { mortar partially missing, partially cracked glass areas and damaged chimneys. }\end{array}$ \\
\hline \hline II & $\begin{array}{l}\text { Medium damage - larger areas of roofing, fascia, glass, demolition of chimneys, larger areas of mortal fallen } \\
\text { off walls and ceilings, smaller cracks in supporting walls, and numerous in separating ones. }\end{array}$ \\
\hline \hline III & $\begin{array}{l}\text { Larger damage - damage on the supporting elements of a roof construction, smaller cracks in construction } \\
\text { elements, (foundations, walls and AB ring beams), bigger cracks or demolition of gable and separating walls }\end{array}$ \\
\hline \hline & $\begin{array}{l}\text { Massive damage - demolition of certain parts of roof construction or obvious deformation, numerous cracks } \\
\text { on pillars, foundations, supporting walls and filled walls, demolition or obvious deformation of separating walls, } \\
\text { occurrence of damages from the former category, disabled installations. Disabled installations are those which } \\
\text { do not function due to the damage caused by the earthquake. }\end{array}$ \\
\hline \hline V & $\begin{array}{l}\text { Massive damage and construction deformation- damages or deformation (dislocation) of certain construc- } \\
\text { tion elements - diagonal cracks in supporting pillars and walls, cracks in construction joints, i.e. disconnections } \\
\text { on supporting walls joints or supporting and filled walls joints, on certain parts of a building, with occurrence of } \\
\text { damage from the former category and other damages which could be repaired, along with installations which } \\
\text { are out of order. Occurrence of damages mentioned above also relates to vertical communications (staircases } \\
\text { and elevators. ) }\end{array}$ \\
\hline
\end{tabular}

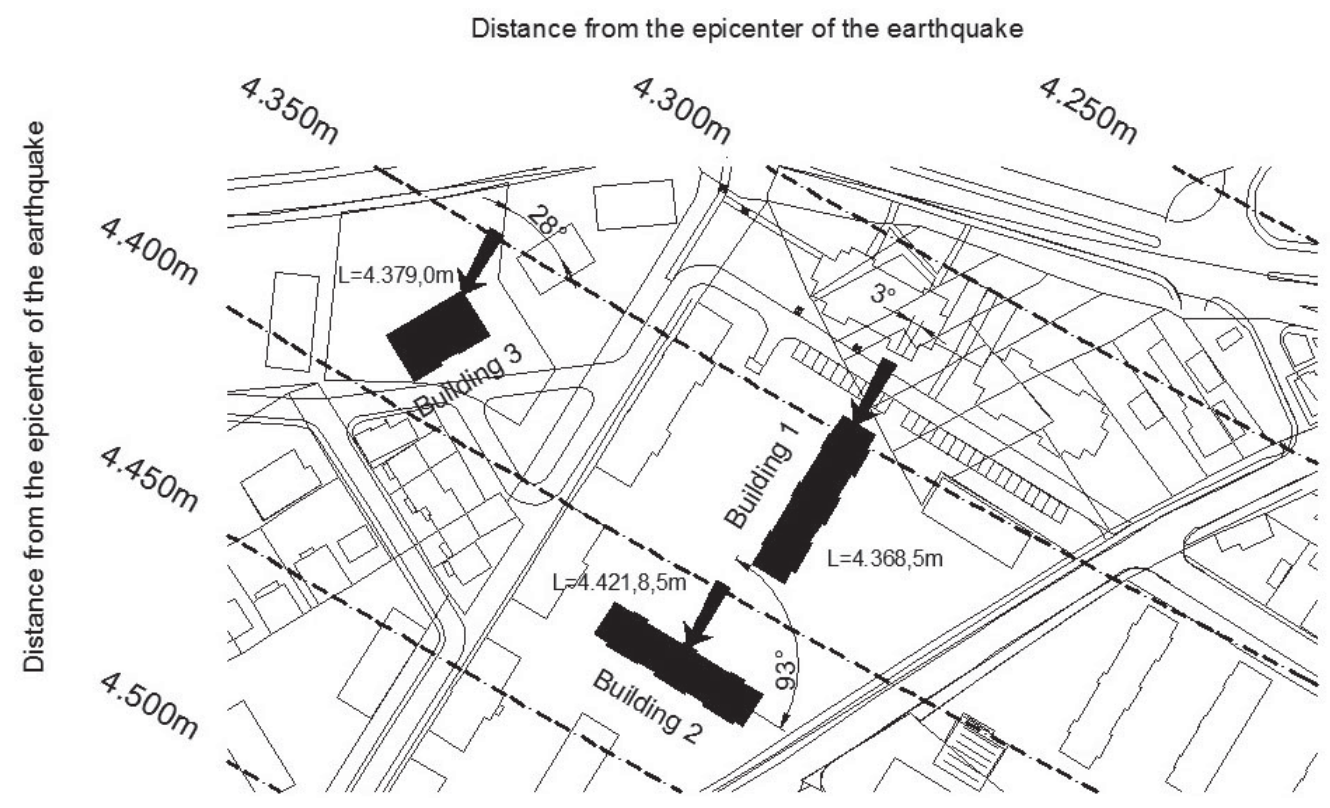

Figure 2. Position of three typical buildings in relation to the epicenter of the earthquake

Figure 2 emphasizes three typical positions of buildings:

- $\quad$ Building 1 - direction of propagation matches the longitudinal axis of a building

- Building 2 - direction of propagation matches the transversal axis of a building and
- Building $3-$ a building covers an angle related to the direction of propagation, so according to the angle $\varphi=28^{\circ}$ the propagation can be distributed, into longitudinal and transversal direction of a building.

In this way, it is possible to analyze the impact of building position and its distance from the epi- 
center on the damage category for all the buildings included in the report.

By analyzing the output data, the basic model for neural network training was defined:

INPUT:

- YOC - Year of construction or the estimated age of a building

- POB - Purpose of a building (residential or business) -

- TNAGS - Total number of the above-ground storeys

- TNS - Total number of storeys (including underground storeys)

- TGAB - Total gross area of a building

- CT - Construction type

- DFE - Distance from the epicenter of the earthquake
- DX - \% of earthquake propagation in the longitudinal direction of a building

- DY - \% of earthquake propagation in the transversal direction of a building.

OUTPUT:

- CBD - Category of the building damage caused by the earthquakeFigure 3 shows the structure of the model.

After forming an appropriate ANN and its training, it is necessary to carry out the analysis of its sensitivity, based on which it is possible to define the influence of every individual input data on its quality. In this way, an opportunity arises to reduce the ANN model, i.e. to eliminate less important input data, which contributes to a more optimal structure.

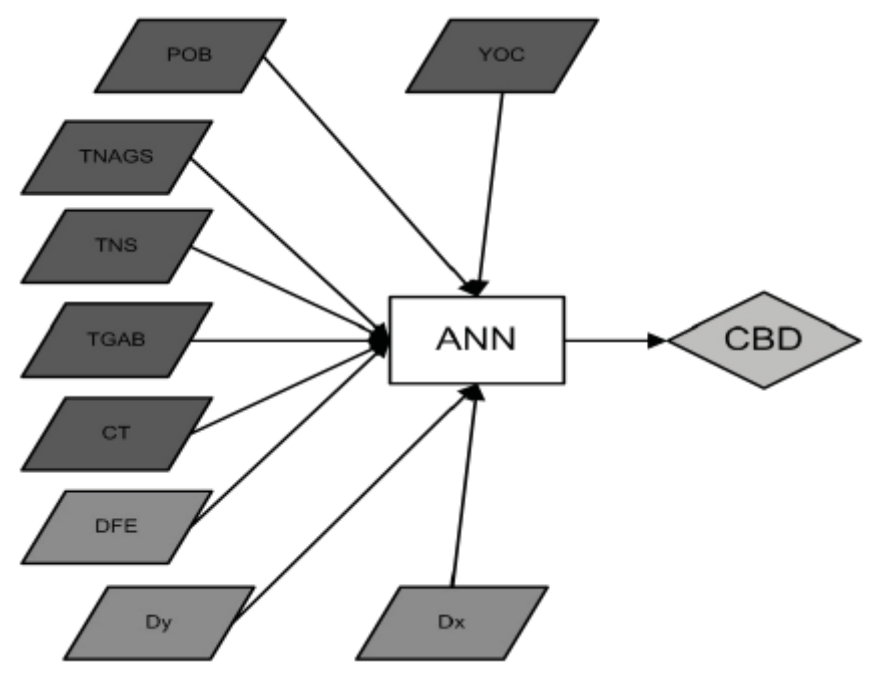

Figure 3 Structure of the ANN model

The data base shortcoming is reflected in the fact that it is formed only upon the propagation of the November 32010 earthquake, of 5.4 degrees of Richter magnitude scale. If an estimation of some future' projected' seismic damages is to be carried out based upon the mentioned data base and the formed ANN, the ANN outputs will not be providing entirely correct results.

Creating a data base upon the reports on the damages caused by November 32010 earthquake, only presents the initial phase in forming a more comprehensive base. While preparing the data base, the features of the earthquake itself were not taken into consi-deration, although they play a highly significant role on the quality of the ANN output data.

In order to be able to get precise predictions about potential seismic damages on buildings by applying a neural network, one must take into consideration the features of the earthquake itself, such as its magnitude, focus depth, etc. This would only be possible through a more comprehensive collecting of data, which requires a prolonged collecting and expanding of the data base, relying upon some future earthquakes.

\section{CONCLUSION}

High-quality functioning of an artificial neural network (ANN) involves creating an adequate data base for its training along with defining input and output data. This paper presented the preparation of a data base for prediction of seismic damage category, by applying artificial neural networks. Forming a data base for damage estimation is based upon reports made immediately after the earthquake in Kraljevo (November 3, 
2010). Data contained in these reports provided a possibility to make connections between building features (ANN input) and the damage category (ANN output). After creating the adequate ANN and its training, it is possible to analyze the network sensitivity, the influence of every individual input data on its quality, reduce the ANN model, i.e. eliminate less important input data and obtain a more optimal structure. ANNs, in other words, present a powerful and adequate tool for prediction of possible damages on buildings, as the grounds for assessment of buildings' vulnerability, with the aim of planning preventive measures of seismic safety.

\section{ACKNOWLEDGEMENTS}

The work reported in this paper is a part of the research within the research project TR 36043 "Development and application of a comprehensive approach to the design of new and safety assessment of existing structures for seismic risk reduction in Serbia", supported by the Ministry for Science and Technology, Republic of Serbia. This support is gratefully acknowledged.

\section{REFERENCES}

1) W.S. McCulloch, W.A. Pitts: „A logical calculus of the ideas immanent in nervous activity", Bulletin of Mathematical Biophysics ,Vol.5, 1943, p.115-133

2) J.H. Garret: „Where and why artificial neural networks are applicable in civil engineering", ASCE, Journal of Computing in Civil Engineering [special issue], Vol.8, 1994; 129130

3) http://www.seismo.gov.rs/Vesti/lzvestaj.pdf (Report on results and activities of the Seismological survey of Serbia after the earthquake near Kraljevo on 03.11.2010 at 01:56 )

4) http://www.ingkomora.org.rs/vesti/?id=1611-2010-001 (Instructions for determining catego 7 ry and damage level on earthquakehit residential buildings, Serbian Chamber of Engineers)

5) J. Dražić: "The Analysis of Interaction of Functional and Structural Building Properties in Aseismic Designing", Doctoral dissertation, University of Novi Sad, Faculty of Technical Sciences, Novi Sad, 2005. (in Serbian)

Paper sent to revision: 07.03.2012.

Paper ready for publication: 29.03.2012. 